E3S Web of Conferences 1, 05008 (2013)

DOI: $10.1051 / \mathrm{e} 3 \operatorname{sconf} / 20130105008$

(c) Owned by the authors, published by EDP Sciences, 2013

\title{
Application of Isotope Dilution Mass Spectrometry for Reference Measurements of Cadmium. Copper, Mercury, Lead, Zinc and Methyl Mercury in Marine Sediment Sample
}

\author{
E. Vasileva and I. A. Wysocka
}

Marine Environment Laboratories, International Atomic Energy Agency, 4 Quai Antoine 1er, MC 98000 Monaco; E.Vasileva-Veleva@iaea.org

\begin{abstract}
Marine sediment was selected as a test sample for the laboratory inter-comparison studies organized by the Environment Laboratoryes of the International Atomic Energy. The analytical procedure to establish the reference values for the $\mathrm{Cd}, \mathrm{Cu}, \mathrm{Hg}$, Methyl $\mathrm{Hg}, \mathrm{Pb}$ and $\mathrm{Zn}$ amount contents was based on Isotope Dilution Inductively Coupled Plasma-Mass Spectrometry (ID ICP-MS applied as a primary method of measurement..The $\mathrm{Hg}$ and Methyl $\mathrm{Hg}$ determination will be detailed more specifically because of the problems encountered with this element, including sample homogeneity issues, memory effects and possible matrix effects during the ICP- MS measurement stage. Reference values, traceable to the SI, with total uncertainties of less than $2 \%$ relative expanded uncertainty $(\mathrm{k}=2)$ were obtained for $\mathrm{Cd}, \mathrm{Cu}, \mathrm{Zn}$ and $\mathrm{Pb}$ and around $5 \%$ for $\mathrm{Hg}$ and $\mathrm{CH}_{3} \mathrm{Hg}$.
\end{abstract}

Key words: ID ICP-MS, cadmium, copper, lead, zinc, mercury, methyl mercury, sediment sample, uncertainty, traceability, validation

\section{Introduction}

The reference values of element amount contents in the marine costal sediment sample were established by the application of measurement procedures based on Isotope Dilution Mass Spectrometry (IDMS) method. Because of its well understood measurement process the IDMS is recognised as primary method of analysis (according to the CCQM definition) [1]. The main advantage of using this technique is obtaining the SI traceable results with low combined uncertainty. The determinations of element amount contents were a part of the procedure used for the preparation of the IAEA candidate certified reference material. In this work five elements $(\mathrm{Cd}, \mathrm{Cu}$, $\mathrm{Hg}, \mathrm{Pb}, \mathrm{Zn}$ ) present in the sediment at the very different levels (from $0.049 \mathrm{mg} / \mathrm{kg} \mathrm{Hg}$ to $156 \mathrm{mg} / \mathrm{kg} \mathrm{Zn}$ ) were determined by IDMS.

\section{Materials and Methods}

Five certified isotopic reference materials were used in these measurements for the blends preparation $\left({ }^{111} \mathrm{Cd}\right.$ from IRMM-622, ${ }^{202} \mathrm{Hg}$ from IRMM-640, ${ }^{65} \mathrm{Cu}$ from IRMM-632, $\quad{ }^{206} \mathrm{~Pb}$ from NIST-991, ${ }^{68} \mathrm{Zn}$ from
IRMM-654). The blends were prepared by weighing of the aliquots of the sample and the optimised masses of the isotopic certified reference materials (spikes). Then the blends were digested in the closed microwave system in the mixture of acids. Before the analyses samples were appropriately diluted or in case of cadmium the matrix separation was carried out. The isotopic ratios of cadmium, copper and zinc were measured by two types of inductively coupled plasma mass spectrometers: the quadrupole (Q-ICPMS, XSERIES, Thermo Scientific) and sector field high resolution (SF-HR-ICP-MS, ATTOM, NU Instruments). At the aim of minimizing the influence of spectral interferences on the results the Collision Cell Technology (CCT) or medium resolution were used. The medium resolution (MR-ICP-MS) was applied for copper and zinc isotopic ratio measurements and the Q-ICP-MS with CCT mode was used for Cd and $\mathrm{Cu}$ isotopic ratio analyses.

\section{Results and Discussion}

The IDMS measurement step was validated according to the requirements of ISO/IEC 17025. The validation of the measurement process encompassed: 1 . Using isotopic 
Table 1. Main contributors to the total uncertainty on the total copper mass fraction

\begin{tabular}{|l|l|l|l|}
\hline Uncertainty contribution & \multicolumn{1}{|c|}{$\begin{array}{c}\text { SF-ICP-MS, } \\
\text { MR }\end{array}$} & $\begin{array}{c}\text { Q-ICP-MS, } \\
\text { standard mode }\end{array}$ & $\begin{array}{c}\text { Q-ICP-MS, } \\
\text { CCT mode }\end{array}$ \\
\hline Uncertainty on ${ }^{65} \mathrm{Cu}$ concentration in spike & $60.4 \%$ & $83.2 \%$ & $85.1 \%$ \\
\hline Correction for dead time effects & $16.2 \%$ & $1.2 \%$ & $0.9 \%$ \\
\hline Correction for mass discrimination effects & $9.6 \%$ & $2.7 \%$ & $1.9 \%$ \\
\hline Correction for blend ratio measurements & $7.9 \%$ & $4.8 \%$ & $4.1 \%$ \\
\hline Correction for moisture content & $3.3 \%$ & $4.5 \%$ & $4.6 \%$ \\
\hline Correction for sample weighing & $1.9 \%$ & $2.7 \%$ & $2.7 \%$ \\
\hline Others & $0.7 \%$ & $0.9 \%$ & $0.7 \%$ \\
\hline
\end{tabular}

CRMs for blend preparation and for mass discrimination corrections. 2. Identification of the majority of potentially significant factors influencing the results (the isotopic equilibrium, ICP-MS parameters, the procedural blank, moisture content, memory effect, the isotopic ratio stability, dead time). 3. Mathematical modelling of the entire measurements process and demonstrating the traceability to the mole or kilogram SI units. 4.

The estimation of the combined uncertainty of the results was done according to the ISO/GUM guide. 5 . Comparative studies of the different analytical procedures and applying two types of instruments (Q-ICP-MS, SF-HR-ICP-MS) for measurements. The adequate results obtained by applying different analytical approaches were identical within the range of the expended uncertainty. Estimated combined uncertainties for $\mathrm{Cd}, \mathrm{Cu}, \mathrm{Pb}$ and $\mathrm{Zn}$ were around $2 \%$, only in case of mercury the expended uncertainty was $3.6 \%$. The total uncertainty budget was calculated on the basis of the IDMS equation by using the method of propagation of standard uncertainties according to ISO guidelines. The main uncertainty contributions to the total uncertainty in the case of $\mathrm{Cu}$ are presented in Table 1.

\section{Conclusion}

ID ICP-MS applied as a primary method of measurements for environment matrices leads to SI traceable values with small combined uncertainties. In conclusion, the obtained results have shown that three measurements approaches used in this studies have given identical values within the range of uncertainty.

\section{References}

Taylor Ph., Kipphardt H., De Bievre P, The definition of primary method of measurement of the "highest metrological quality":challenge in understanding and communication. Accred. Qual. Assur. 2001; 6: 103-106. 